\title{
CORRIGENDUM
}

Genes \& Development 30: 2286-2296 (2016)

\section{Corrigendum: A noncanonical auxin-sensing mechanism is required for organ morphogenesis in Arabidopsis}

Sara Simonini, Joyita Deb, Laila Moubayidin, Pauline Stephenson, Manoj Valluru, Alejandra Freire-Rios, Karim Sorefan, Dolf Weijers, Jiří Friml, and Lars Østergaard

We have realized that there is an error in Figure 4 of the above-mentioned article. By mistake, the images in Figure 4 , A and $\mathrm{D}$, originate from the same sample. This image is from the untreated control experiment (Fig. 4A) but was mistakenly also used in Figure 4D (2,4-D treatment). We have built a revised Figure 4 in which we corrected this error.

Moreover, we have added a raw data file as an Additional Supplemental Material link associated with the original article with the raw images of three independent experiments that were used for the quantification in Figure 4E (Figure_4_raw_ data.pdf). For each condition, we have included a picture taken with a low magnification (a 10× objective). In addition, we have included four more images at higher magnification (a 20x objective) and have repeated the intensity quantification using the nuclei that are labeled with a number. The values are summarized below the images, and a new chart has been built with these data, including a new ANOVA analysis. These data show the same result as in the original Figure 4 .

The authors apologize for this error.
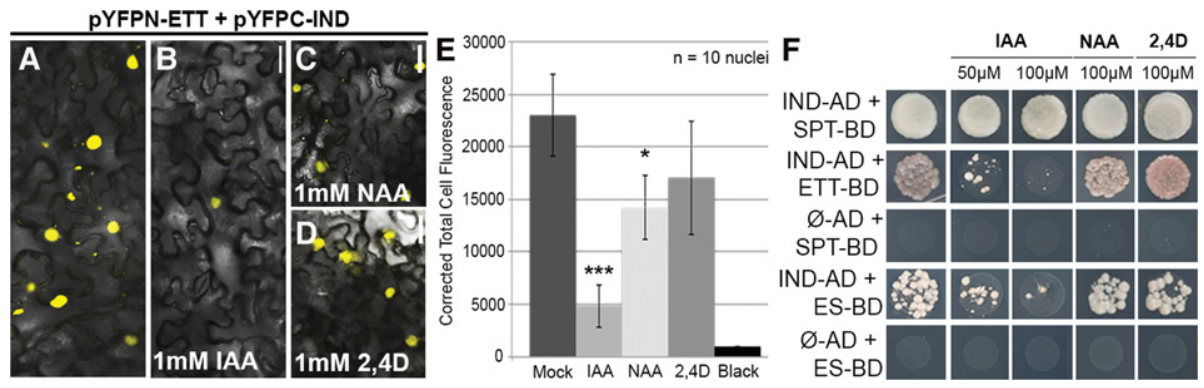

Figure 4. ETT and IND protein interact in an IAA-sensitive manner. $(A-D)$ BiFC with $p Y F P N-E T T$ and $p Y F P C-I N D$ in the absence $(A)$ and presence of IAA $(B)$, NAA $(C)$, and 2,4-D $(D)$. All hormonal treatments were with $1 \mathrm{mM}$ in lanolin. (E) Fluorescence quantification $(C T C F)$ of split YFP signal between ETT and IND without treatment and with IAA, NAA, and 2,4-D. $\left({ }^{*}\right) P<0.01 ;\left({ }^{* * *}\right) P<0.0001$. Error bars show the standard deviation. $(F) \mathrm{Y} 2 \mathrm{H}$ assays with increasing concentration of IAA, NAA, and 2,4D. Bars: $A-D, 50 \mu \mathrm{m}$. 


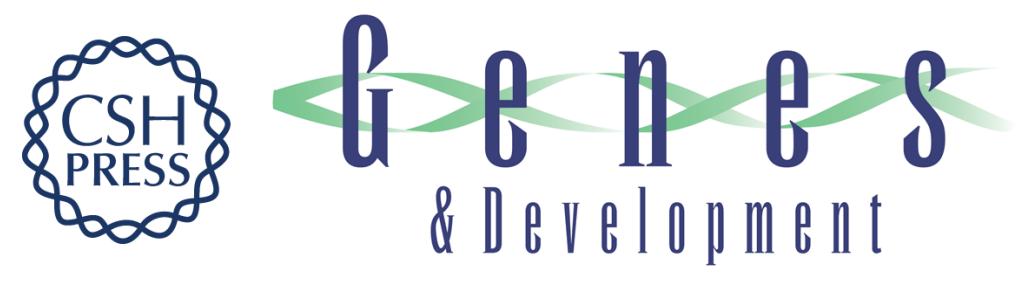

\section{Corrigendum: A noncanonical auxin-sensing mechanism is required for organ morphogenesis in Arabidopsis}

Sara Simonini, Joyita Deb, Laila Moubayidin, et al.

Genes Dev. 2017, 31:

Access the most recent version at doi:10.1101/gad.306985.117

\section{Related Content \\ A noncanonical auxin-sensing mechanism is required for organ morphogenesis in Arabidopsis \\ Sara Simonini, Joyita Deb, Laila Moubayidin, et al. \\ Genes Dev. October , 2016 30: 2286-2296 \\ License \\ Email Alerting \\ Receive free email alerts when new articles cite this article - sign up in the box at the top \\ Service right corner of the article or click here.}

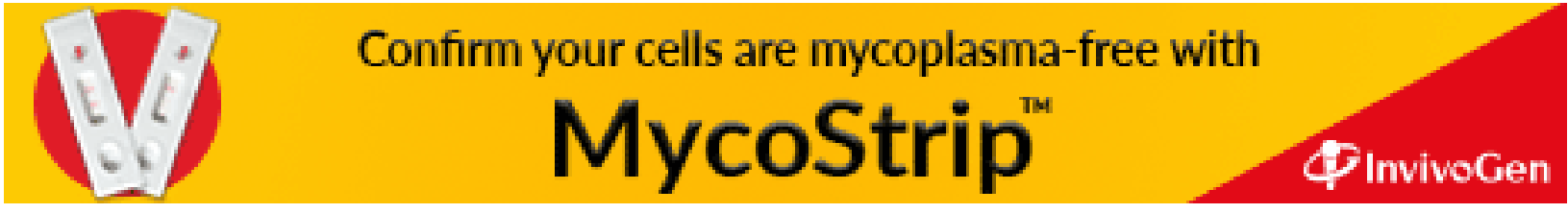

